\title{
10 health stories that mattered Oct. 14-18, 2013
}

- Health Canada announced it will improve how it informs the public about risks related to drug recalls. Based on the findings of an independent report into the recall of Alysena 28 birth control pills, Health Canada stated it will take actions such as strengthening 24/7 response capabilities and clarifying language used in recalls.

- Marijuana dispensing machines may be coming to Canada. US-based Medbox Inc. announced that it has partnered with a licensed medical cannabis laboratory and cultivation centre in Canada. The company states that its machines could serve as secure "medicine vaults" in cultivation centres and doctors' offices.

- The proposed Charter of Quebec Values to ban the wearing of religious symbols would have negative effects on mental health, well-being and social integration, according to a letter by a large group of mentalhealth practitioners, researchers and educators. Religious practices make up part of many people's cultural identity, states the letter, and recognition "of cultural identity is important for the mental health and well-being of individuals and communities."

- The potential adverse health effects of stun guns are ill-understood, according to an expert-panel report.
Though fatal respiratory and cardiac complications are rare, there is a need for higher-quality research and better reporting of adverse events, the panel concluded.

- Hypertension Canada has raised its daily recommended sodium intake to $2000 \mathrm{mg}$. It is likely not feasible for Canadians, who on average consume $3400 \mathrm{mg} / \mathrm{day}$, to reduce their intake to the previously recommended $1500 \mathrm{mg} /$ day, a member of the task force making the recommendation told The Globe and Mail.

- The number of people with severe gambling problems doubled in British Columbia between 2002 and 2007, according to a report from the province's Ministry of Health. "My report examines the inherent challenges that government faces in seeking to raise revenue while not increasing social harms, and makes a number of evidence-based recommendations for government to consider," Provincial Health Officer Dr. Perry Kendall stated in a press release.

- Nearly $40000 \mathrm{~kg}$ of unused and expired prescription drugs were returned to drug stores in response to a three-month campaign by the Partnership for a Drug Free Canada and Shoppers Drug Mart. The campaign was launched to help reduce the amount of prescription medications available for abuse by teenagers.

- "Breastfeeding is not just for newborns," declares a government poster that has provoked a strong response online. The image of a mother breastfeeding an older child links to a Public Health Agency of Canada article recommending that mothers breastfeed for "up to 2 years and beyond."

- The idea of opening a safe injection site is being discussed in London, Ontario, to reduce drug overdoses and disease transmission. Strong opposition to the idea is expected, however, and local police and the mayor have both stated it is premature to voice an opinion on the subject, reports The London Free Press.

- Two residents of Alberta are mounting a legal challenge against the province's ban on private medical insurance. The Albertans, who combined to pay more than $\$ 100000$ for surgeries in the United States rather than remain on waiting lists, suggest that lack of access to private health care infringes their right to "life, liberty and security of person," reports the Calgary Herald. — Roger Collier, CMAJ

CMAJ 2013. DOI:10.1503/cmaj.109-4635 